\title{
Evaluation of downsized homograft conduits for right ventricle-to-pulmonary artery reconstruction
}

\author{
David Michael McMullan, MD, ${ }^{a}$ Guido Oppido, MD, ${ }^{a}$ Nelson Alphonso, MD, ${ }^{a}$ Andrew Donald Cochrane, MD, ${ }^{a, b}$ \\ Yves d'Udekem d'Acoz, MD, ${ }^{a, b}$ and Christian P. Brizard, MD ${ }^{a, b}$
}

Objective: Although homograft conduits are frequently used to establish right ventricle-to-pulmonary artery continuity, the limited availability of small-size homografts is a significant constraint in pediatric cardiac surgery. We compared the performance of standard homograft conduits with that of surgically reduced bicuspid homograft conduits in patients undergoing repair of truncus arteriosus.

Methods: Forty infants undergoing complete repair of truncus arteriosus with either standard homografts $(n=26)$ or reduced-size bicuspid homografts $(n=14)$ were evaluated.

Results: The median downsized conduit diameter $(13 \mathrm{~mm})$ was similar to the standard homograft diameter $(12 \mathrm{~mm}, P=.52)$. There were 6 early deaths and 5 late deaths, representing an overall 30-day mortality of $15 \%$ and a 5-year mortality of $25 \%$. No deaths were directly related to homograft dysfunction. Four (29\%) downsized conduits and $8(31 \%)$ standard conduits required replacement at a median interval of 18.5 months and 42.4 months, respectively. Catheter-based interventions were required in $5(36 \%)$ patients in the downsized group and in $3(12 \%)$ patients in the standard group. There was no difference in freedom from surgical or catheter-based reintervention between the 2 groups $(P=.42)$. Freedom from conduit failure (severe conduit stenosis, moderate or greater regurgitation) was $55.9 \%$ and $17.2 \%$ at 3 years in the downsized and standard groups, respectively.

Conclusion: The surgically downsized homograft is an excellent option when an appropriate-sized homograft is not available and might prevent morbidity associated with the use of an oversized conduit.

From the Cardiac Surgery Unit, The Royal Children's Hospital, ${ }^{\mathrm{a}}$ and the Department of Pediatrics, The University of Melbourne, ${ }^{\mathrm{b}}$ Melbourne, Victoria, Australia.

Received for publication June 2, 2005; revisions received Jan 3, 2006; accepted for publication Feb 17, 2006.

Address for reprints: Christian Pierre Robert Brizard, MD, Cardiac Surgery Unit, The Royal Children's Hospital, Flemington Rd, Parkville, Victoria, 3052, Australia (E-mail: christian.brizard@rch.org.au).

J Thorac Cardiovasc Surg 2006;132:66-71

$0022-5223 / \$ 32.00$

Copyright $(\odot) 2006$ by The American Association for Thoracic Surgery

doi:10.1016/j.jtcvs.2006.02.041
$\mathrm{R}$ econstruction of the right ventricular outflow tract in patients with congenital heart disease frequently requires creation of a right ventricle (RV)-topulmonary artery (PA) conduit to establish continuity of the pulmonary circulation. Several types of valved conduits have been used successfully for this purpose, including aortic and pulmonary homografts, ${ }^{1-3}$ composite bioprosthetic conduits, ${ }^{4}$ xenografts, ${ }^{5}$ autologous pericardial valved conduits, ${ }^{6}$ and valved venous xenografts. ${ }^{7}$ Although homografts are generally preferred because they have greater freedom from reintervention and are technically easier to sew than composite (Dacron) valved conduits, ${ }^{8}$ the shortage of small-size homografts remains a significant limitation. The use of surgically downsized homografts has been described. ${ }^{9-12}$ One report has suggested early and midterm functional equivalency between downsized and nondownsized homografts. ${ }^{13}$ However, the study also describes a disproportionately high number of early deaths in the downsized group, which might reflect disparate patient populations with respect to underlying anatomic defects and surgical indications. In the current study we retrospectively compared the use of downsized homografts and standard homografts for RV-PA reconstruction in patients undergoing repair of truncus arteriosus. 


$$
\begin{aligned}
& \text { Abbreviations and Acronyms } \\
& \begin{aligned}
\mathrm{CI} & =\text { confidence interval } \\
\mathrm{ECMO} & =\text { extracorporeal membrane oxygenation } \\
\mathrm{PA} & =\text { pulmonary artery } \\
\mathrm{RV} & =\text { right ventricle } \\
\mathrm{Vmax} & =\text { maximum velocity }
\end{aligned}
\end{aligned}
$$

TABLE 1. Conduit use over time

\begin{tabular}{ccc}
\hline Year & Downsized & Standard \\
\hline 1995 & 0 & 2 \\
1996 & 2 & 3 \\
1997 & 5 & 3 \\
1998 & 0 & 6 \\
1999 & 1 & 0 \\
2000 & 0 & 4 \\
2001 & 1 & 1 \\
2002 & 4 & 2 \\
2003 & 0 & 2 \\
2004 & 1 & 3 \\
Total & 14 & 26 \\
\end{tabular}
complete surgical correction of truncus arteriosus. Fourteen of these patients (median age, 56 days; range, 17-161 days) received a surgically downsized aortic $(n=8)$ or pulmonary $(n=6)$ conduit because of the unavailability of an appropriately sized homograft. The remaining 26 patients (median age, 46 days; range, $3-673$ days) received a standard aortic $(n=12)$ or pulmonary $(\mathrm{n}=$ 14) homograft conduit. Four $(29 \%)$ patients in the downsized group and $6(23 \%)$ patients in the standard group were less than 30 days of age at the time of the operation. Three patients in the standard group had coexisting interrupted aortic arch or severe coarctation and underwent concomitant arch reconstruction.

All patients underwent transthoracic echocardiographic examination before discharge from the hospital. Subsequent echocardiography was performed during routine clinical visits and if a change in symptoms, physical findings, or clinical status was observed. Study end points included mortality, freedom from conduit replacement or reintervention, and freedom from clinically significant conduit stenosis or insufficiency (severe stenosis or moderate or greater insufficiency).

In this study conduit replacement was defined by surgical replacement of the conduit with another conduit. Catheter intervention was defined by balloon dilation of conduit stenosis with or without stenting. This study was done within the guidelines established by our institutional human research ethics committee.

\section{Operative Technique}

All patients underwent complete surgical correction as the initial procedure. Surgical correction was performed on full-flow cardiopulmonary bypass by using intermittent antegrade cold blood cardioplegia. In patients with type I or II truncus, the PA was divided close to the common arterial trunk, and the resultant truncal defect was closed directly. When the PAs arose separately, the common trunk was completely transected. The PAs were then separated proximally, and the truncal root was reconstructed by using an end-to-end anastomosis. A longitudinal ventriculotomy was performed along the anterior surface of the right ventricular outflow tract to the base of the common trunk. The ventricular septal defect was closed with a patch of autologous pericardium treated with glutaraldehyde. When present, atrial septal defects were closed primarily. In patients with type I truncus, the common PA was anastomosed directly to the distal end of the conduit with running polypropylene sutures. When the PAs arose separately, they were prepared by performing a partial (one-third circumference) anastomosis to each other before direct anastomosis to the distal end of the conduit. Proximal branch pulmonary arterioplasty

was performed when small-branch PAs were encountered. The choice of aortic versus pulmonary homografts was based solely on availability. However, a pulmonary homograft was preferentially selected when both were available. The distribution of standard and downsized techniques used over the course of the study is reported in Table 1 .

Homografts were trimmed at the commissural level to facilitate placement of the valve as close as possible to the PA bifurcation and to prevent conduit valve compression or distortion by the sternum. The RV-PA conduit was anastomosed to the RV by using glutaraldehyde-treated pericardium or Gore-Tex for the construction of an anterior hood. The patient was then separated from cardiopulmonary bypass support, and the chest was closed.

\section{Method of Homograft Downsizing}

Cryopreserved homografts were downsized according to the technique described by Michler and colleagues. ${ }^{9}$ After trimming the homograft to the appropriate length, 2 parallel longitudinal incisions were made through the valve annulus along the longitudinal axis of the homograft. The incisions were oriented to preserve each of the 3 commissures and 2 leaflets (Figure 1, A). The homograft was then fashioned into a tube again, and a neocommissure was constructed by closing the longitudinal defect with running polypropylene sutures (Figure 1,B). After downsizing, the new effective conduit diameter is approximately two thirds the diameter of the original homograft. In our series surgical downsizing produced a $31 \% \pm 5 \%$ reduction in mean homograft diameter, as assessed with Hegar dilators.

\section{Diagnostic Studies}

All patients were evaluated by means of transthoracic echocardiography during the early postoperative period and before hospital discharge. Patients were followed with routine transthoracic echocardiograms on an annual or semiannual basis. Interval echocardiographic examinations were performed for new symptoms or new findings on physical examination. For the purpose of this study, conduit insufficiency was classified as trivial, mild, moderate, or severe. Conduit stenosis was defined as mild (peak pressure gradient, 16-30 mm Hg; maximum velocity [Vmax], 2-2.7 m/s), moderate (peak pressure gradient, 30-50 mm Hg; Vmax, 2.8-3.5 m/s), and severe (peak pressure gradient, $>50 \mathrm{~mm} \mathrm{Hg}$; Vmax, $>3.5 \mathrm{~m} / \mathrm{s}$ ). 

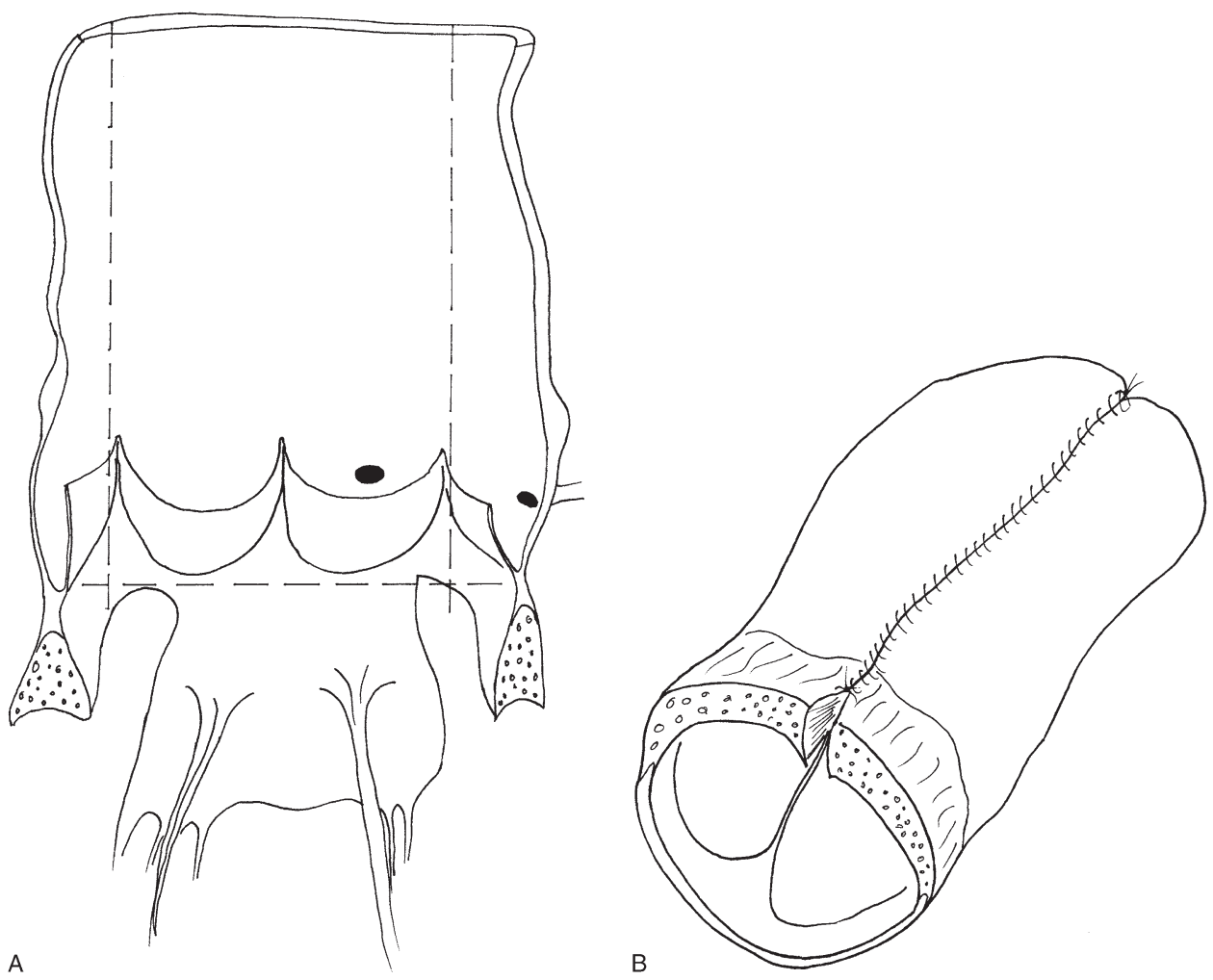

Figure 1. The technique used to downsize aortic homografts. Homograft trimming is represented by dashed lines (a). Note that all 3 commissures are preserved after trimming. The completed homograft is also depicted (b). The technique for pulmonary homograft downsizing is identical.

Cardiac catheterization was performed when clinically significant conduit or branch PA stenosis was suggested by echocardiography. A conduit failure event was defined by the onset of severe stenosis, moderate or greater regurgitation, or both. Conduit replacement was performed only when severe conduit stenosis was present. Balloon angioplasty with or without endovascular stenting was performed when stenotic lesions appeared amenable to transcatheter intervention.

\section{Statistical Methods}

Unless otherwise specified, data are expressed as median group values. Statistical analysis was performed with Stata Version 8 software (StataCorp LP, College Station, Tex). Groups were compared by using unpaired $t$ tests. Survival analysis was performed by using the Kaplan-Meier method, and comparison of survival curves was performed by using the log-rank method.

\section{Results}

The patients in the downsized and standard groups were similar with respect to median body surface area, age at operation, and median implanted conduit diameter. The downsized group of patients had a slightly greater weight at the time of the operation (Table 2). In the downsized group the median homograft diameter was $19 \mathrm{~mm}$ (range, 15-21 mm) before downsizing and $13 \mathrm{~mm}$ (range, 10-16 $\mathrm{mm}$ ) after downsizing.
There were 6 early deaths in this series, representing an overall 30-day mortality of $15 \%$. One patient in the downsized group died at 20 days of progressive respiratory failure and inability to wean from extracorporeal membrane oxygenation (ECMO) after intraoperative intrapulmonary hemorrhage. Five early deaths in the standard group occurred at 1 day (dysrhythmia), 1 day (dysrhythmia), 4 days (withdrawal of ECMO support that was instituted for ventricular failure and acidosis), 12 days (cardiovascular collapse caused by septic meningitis), and 13 days (withdrawal of ECMO support that was instituted at the time of repair).

Median patient follow-up for the series was 66.4 months (range, 24 days to 9.6 years). Follow-up survival and reintervention data were complete for all patients. During a median follow-up of 61.9 months (range, 9.5 months to 8.5 years), there was one additional death in the downsized group. The patient died at 33 days of sepsis. Actuarial survival in the downsized group was $84 \%$ (confidence interval [CI], 51\%$96 \%$ ) at 5 years. During a median follow-up of 74.3 months (range, 24 days to 9.6 years), there were 4 additional deaths in the standard group. These patients died at 59 days (septic shock), 62 days (respiratory arrest caused by bronchiolitis), 91 days (pulmonary hypertensive crisis and dysrhythmia), 
TABLE 2. Patient characteristics

\begin{tabular}{lccc}
\hline & $\begin{array}{c}\text { Standard group } \\
(\mathbf{n}=\mathbf{2 6})\end{array}$ & $\begin{array}{c}\text { Downsized group } \\
(\mathbf{n}=\mathbf{1 4})\end{array}$ & $\begin{array}{c}\boldsymbol{P} \\
\text { value }\end{array}$ \\
\hline Body surface area $\left(\mathrm{m}^{2}\right)$ & 0.21 & 0.21 & .15 \\
Age (d) & 46.0 & 55.5 & .48 \\
Weight $(\mathrm{kg})$ & 3.5 & 4.1 & .05 \\
Conduit diameter $(\mathrm{mm})$ & 12 & 13 & .52 \\
$\quad \begin{array}{l}\text { Indexed to body surface } \\
\quad \text { area }\left(\mathrm{mm} / \mathrm{m}^{2}\right)\end{array}$ & 56 & 54 & .48 \\
\end{tabular}

and 114 days (unknown cause of death at home). Actuarial survival in the standard group was $70 \%$ (CI, $47 \%-84 \%$ ) at 5 years. There was no survival difference between the 2 groups $(P=.35)$. No deaths in this series appeared to be directly related to homograft dysfunction. All surviving patients were in New York Heart Association class I at the latest follow-up.

\section{Conduit Replacement or Catheter Intervention}

Fourteen $(35 \%)$ patients required conduit replacement or catheter intervention in this series after a median interval of 28.1 months (range, 7 days to 7.2 years), representing an overall freedom from conduit replacement or catheter intervention of $47 \%$ (CI, 25\%-69\%) at 5 years (Figure 2). Four (29\%) downsized conduits required replacement at a median interval of 18.5 months (range, 7 days to 45 months) after implantation. One of these was replaced on the seventh postoperative day because of the concern that extreme conduit dilation, caused by severe suprasystemic pulmonary hypertension, was distorting the branch PAs. At the time of the operation, the ventricular septal defect patch was fenestrated, and the 14-mm downsized conduit was replaced with a 10-mm standard pulmonary homograft. All other conduits were replaced because of severe conduit stenosis. The median interval for conduit replacement caused by conduit stenosis in the downsized group was 27.2 months (range, 9.7-45 months). Eight (31\%) standard conduits required replacement at a median interval of 42.4 months (range, 21.2-98.3 months) after implantation.

Catheter interventions were required in $5(36 \%)$ patients in the downsized group. Three patients underwent balloon dilation with or without stenting of one or both branch PAs at 3.8, 4.5, and 11.3 months, respectively. Balloon dilation of severe conduit stenosis was required in 2 patients at 39.7 and 51.3 months, respectively. One of these patients underwent balloon dilation of the conduit and branch PAs. Catheter-based interventions were required in $3(12 \%)$ patients in the standard group. No patients in the standard group required early surgical intervention. Three patients underwent balloon dilation with or without stenting for severe conduit stenosis at $6.6,12.6$, and 24.1 months, respectively. There was no difference in freedom from surgi-

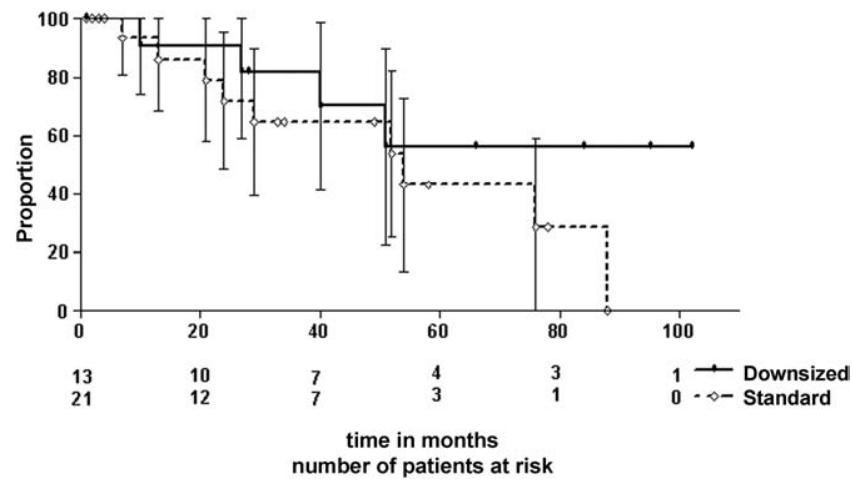

Figure 2. Kaplan-Meier freedom from conduit replacement or catheter-based intervention in standard and downsized homograft conduits.

cal or catheter-based reintervention between the 2 groups, as determined by using the log-rank test for equality $(P=.42$, Figure 2).

One patient required surgical revision on the first postoperative day to correct critical narrowing at the distal anastomosis. This intervention was not included in the statistical analysis.

\section{Conduit Function}

At the latest follow-up (median, 61.9 months; range, 9.5101.8 months), 8 (57\%) patients in the downsized group have not required conduit replacement. One of these patients has severe conduit stenosis, 6 have moderate conduit stenosis, and 1 is free of conduit stenosis. Conduit regurgitation is severe in 1 , moderate in 3 , and mild or trace in 4 patients. Freedom from severe conduit stenosis or moderatesevere regurgitation was $55.9 \%(\mathrm{CI}, 25.9 \%-85.9 \%)$ at 3 years (Figure 3). At the latest follow-up (median, 47.3 months; range, 0.8-115.2 months), 9 (35\%) patients in the standard group have not required conduit replacement. One of these patients has severe conduit stenosis, 5 have moderate conduit stenosis, 1 has mild conduit stenosis, and 2 are free of conduit stenosis. Conduit regurgitation is severe in 1 , moderate in 2, mild or trace in 2 , and absent in 4 patients in the standard group. Freedom from severe conduit stenosis or moderate or severe regurgitation was $17.2 \%$ (CI, $0 \%-38.1 \%$ ) at 3 years, which is not statistically different than that observed in the downsized group $(P=.058$, Figure 3$)$.

For both the downsized and standard groups, the aortic and pulmonary homografts demonstrated comparable probability of freedom from failure $(P=.31$ and $P=.45$, respectively).

\section{Discussion}

Replacement or reconstruction of the RV-PA outflow tract is performed frequently as part of complex surgical repairs for severe congenital heart defects. The ideal surgical RV-PA 


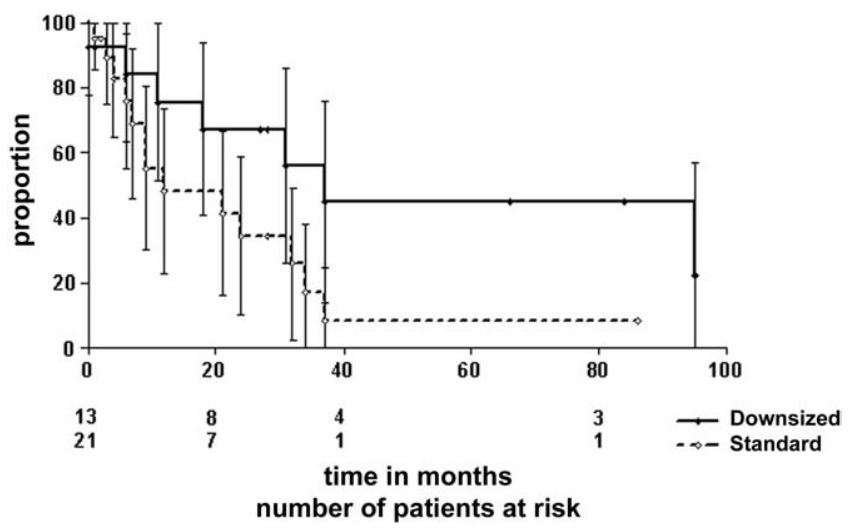

Figure 3. Kaplan-Meier freedom from failure events (severe stenosis, moderate or greater insufficiency) in standard and downsized homograft conduits.

conduit would provide long-term unobstructed forward flow and valve competency. Most currently available conduits, including homografts, ${ }^{1-3}$ composite bioprosthetic conduits, ${ }^{4}$ pulmonary xenografts, ${ }^{5}$ autologous pericardial valved conduits, ${ }^{6}$ and valved venous xenografts, ${ }^{7}$ provide excellent initial valve competency and flow characteristics. However, progressive conduit stenosis and valve dysfunction often develop over time, necessitating early conduit replacement.

In general, composite xenograft conduits are more prone to calcification and early failure than homografts, with significant right ventricular outflow tract obstruction occurring in up to $77 \%$ of patients within 12 months of xenograft implantation in patients younger than 1 year. ${ }^{14}$ Actuarial freedom from reintervention after implantation ranges from $48 \%$ at 18 months $^{4}$ to $64 \%$ at 4 years, ${ }^{15}$ depending on the type of conduit used. Limited stentless xenograft root conduit durability has also been reported, ${ }^{5}$ and stentless conduits are not available in small sizes.

In most institutions aortic and pulmonary homografts are the preferred conduits used for RV-PA reconstruction because they offer improved valve durability and are technically easier to sew than composite (Dacron) valved conduits. ${ }^{8}$ The longevity of homograft conduits varies widely, with reported freedom from homograft replacement ranging from approximately $50 \%$ at 3 years $^{2}$ to approximately $75 \%$ at 10 years. ${ }^{1}$ Conduit stenosis remains the most common indication for reintervention. ${ }^{16}$ Limited availability of small-size homografts is a significant constraint to their use as conduits, and the trend toward earlier surgical intervention across the spectrum of cardiac defects might further limit the availability of appropriately sized homografts.

Michler and colleagues ${ }^{9}$ initially reported a technique for surgically downsizing homograft conduits by excising one leaflet. Subsequently, several groups have reported limited clinical experience with similar techniques to reconstruct the right ventricular outflow tract. ${ }^{10-12}$ Although downsized homograft conduits exhibit excellent initial valve competence and flow characteristics in vitro, ${ }^{17}$ their long-term clinical performance has not been well defined. Koirala and associates ${ }^{13}$ recently described their experience with downsized homograft conduits. In their series they reported that downsized homografts exhibit early and midterm valve function that is similar to that seen with standard homografts. However, the retrospective study also reports a disproportionately high number of early deaths (38\%) in the group undergoing downsized conduit placement, which might reflect disparate patient populations with respect to underlying anatomic defects and surgical indications.

In the current study we compared the use of downsized homografts and standard homografts for RV-PA reconstruction exclusively in patients undergoing repair of truncus arteriosus to exclude differences in underlying anatomy and pathophysiologic complexity. There were 6 hospital deaths in our series, representing a 30 -day mortality of $15 \%$. No deaths appeared to be directly related to homograft dysfunction. In all cases the decision to use a downsized conduit was based solely on the lack of availability of an appropriately sized homograft.

Small conduit diameter has been described as a risk factor for early conduit failure in young patients. ${ }^{18}$ In our series the measured and normalized diameters of downsized homografts were similar to those in the nondownsized group. Although oversized homografts can be used as RV-PA conduits, ${ }^{12}$ limited space within the mediastinal cavity might preclude their use in many patients. We believe that one early death in our series is attributable to the use of a disproportionately large nondownsized conduit. In this case a $17-\mathrm{mm}\left(70.3 \mathrm{~mm} / \mathrm{m}^{2}\right)$ conduit was used in a $4.0-\mathrm{kg}$ patient. The patient was hemodynamically stable in the early postoperative period but experienced hypotension and cardiac arrest shortly after delayed sternal closure. Postmortem review suggested right ventricular compression by the homograft. In the case of the patient in whom a downsized conduit was replaced at 7 days, we believe that fixed severe pulmonary hypertension contributed to dilation of the homograft, which produced branch PA distortion.

Patients who received a downsized homograft in this series had a $44.7 \%$ predicted freedom from severe conduit stenosis or moderate or severe regurgitation at 5 years compared with $8.6 \%$ in the standard group (Figure 3). Furthermore, in both the standard and downsized groups, no differences between aortic and pulmonary homografts were observed.

These results are somewhat better than those reported for nondownsized homografts in infants, in which freedom from allograft dysfunction ranges from $37 \%^{19}$ to $54 \%^{2}$ at 2 years. Moreover, freedom from allograft dysfunction is 
closer to $80 \%$ at 2 years when larger $(12-15 \mathrm{~mm})$ homografts are used. ${ }^{2}$

In this series the overall freedom from surgical or catheterbased reintervention was the same for patients receiving either downsized or standard homografts for RV-PA reconstruction during repair of truncus arteriosus. No difference in downsized or standard conduit performance or longevity was observed in this study, irrespective of whether an aortic or pulmonary homograft was used.

In conclusion, we believe that the surgically downsized homograft is an excellent option when an appropriately sized homograft is not available and might prevent morbidity associated with the use of an oversized conduit.

\section{References}

1. Alexiou C, Keeton BR, Salmon AP, Monro JL. Repair of truncus arteriosus in early infancy with antibiotic sterilized aortic homografts. Ann Thorac Surg. 2001;71(suppl):S371-4.

2. Perron J, Moran AM, Gauvreau K, del Nido PJ, Mayer JE Jr, Jonas RA. Valved homograft conduit repair of the right heart in early infancy. Ann Thorac Surg. 1999;68:542-8.

3. Forbess JM, Shah AS, St Louis JD, Jaggers JJ, Ungerleider RM. Cryopreserved homografts in the pulmonary position: determinants of durability. Ann Thorac Surg. 2001;71:54-60.

4. Ishizaka T, Ohye RG, Goldberg CS, Ramsburg SR, Suzuki T, Devaney EJ, et al. Premature failure of small-sized Shelhigh No-React porcine pulmonic valve conduit model NR-4000. Eur J Cardiothorac Surg. 2003;23:715-8.

5. Brawn WJ. The use of a glutaraldehyde-preserved ovine pulmonary valve, as a pulmonary valve substitute in infants. Semin Thorac Cardiovasc Surg. 1995;7:154-6.

6. Schlichter AJ, Kreutzer C, Mayorquim RC, Simon JL, Roman MI, Vazquez H, et al. Five- to fifteen-year follow-up of fresh autologous pericardial valved conduits. J Thorac Cardiovasc Surg. 2000;119:869-79.

7. Breymann T, Thies WR, Boethig D, Goerg R, Blanz U, Koerfer R. Bovine valved venous xenografts for RVOT reconstruction: results after 71 implantations. Eur J Cardiothorac Surg. 2002;21:703-10.
8. Reddy VM, Rajasinghe HA, McElhinney DB, Hanley FL. Performance of right ventricle to pulmonary artery conduits after repair of truncus arteriosus: a comparison of Dacron-housed porcine valves and cryopreserved allografts. Semin Thorac Cardiovasc Surg. 1995;7:133-8.

9. Michler RE, Chen JM, Quaegebeur JM. Novel technique for extending the use of allografts in cardiac operations. Ann Thorac Surg. 1994;57: 83-7.

10. Monro JL, Tolan MJ, Slavik Z, Salmon AP, Keeton BR. Downsizing of valve allografts for use as right heart conduits. Ann Thorac Surg. 1995;59:789.

11. Santini F, Mazzucco A. Bicuspid homograft reconstruction of the right ventricular outflow tract in infants. Ann Thorac Surg. 1995;60(suppl): S624-5.

12. Tam RK, Tolan MJ, Zamvar VY, Slavik Z, Pickering R, Keeton BR, et al. Use of larger sized aortic homograft conduits in right ventricular outflow tract reconstruction. J Heart Valve Dis. 1995;4:660-4.

13. Koirala B, Merklinger SL, Van Arsdell GS, McCrindle BW, Borger MA, Caldarone CA, et al. Extending the usable size range of homografts in the pulmonary circulation: outcome of bicuspid homografts. Ann Thorac Surg. 2002;73:866-70.

14. Levine AJ, Miller PA, Stumper OS, Wright JG, Silove ED, De Giovanni JV, et al. Early results of right ventricular-pulmonary artery conduits in patients under 1 year of age. Eur J Cardiothorac Surg. 2001;19:122-6.

15. Aupecle B, Serraf A, Belli E, Mohammadi S, Lacour-Gayet F, Fornes $\mathrm{P}$, et al. Intermediate follow-up of a composite stentless porcine valved conduit of bovine pericardium in the pulmonary circulation. Ann Thorac Surg. 2002;74:127-32.

16. Wells WJ, Arroyo H Jr, Bremner RM, Wood J, Starnes VA. Homograft conduit failure in infants is not due to somatic outgrowth. J Thorac Cardiovasc Surg. 2002;124:88-96.

17. Hiramatsu T, Miura T, Forbess JM, Brizard C, Jonas RA. Downsizing of valve allografts for use as right heart conduits. Ann Thorac Surg. 1994;58:339-43.

18. Caldarone CA, McCrindle BW, Van Arsdell GS, Coles JG, Webb G, Freedom RM, et al. Independent factors associated with longevity of prosthetic pulmonary valves and valved conduits. J Thorac Cardiovasc Surg. 2000;120:1022-31.

19. Yankah AC, Alexi-Meskhishvili V, Weng Y, Schorn K, Lange PE, Hetzer R. Accelerated degeneration of allografts in the first two years of life. Ann Thorac Surg. 1995;60(suppl):S71-7.

\section{The Journal of Thoracic and Cardiovascular Surgery Conflict of Interest Policy}

To assure fairness to authors submitting work for consideration in The Journal of Thoracic and Cardiovascular Surgery, a mechanism exists for managing conflicts of interest. The editor and each of the section editors complete a "Conflict of Interest" form that identifies any and all relationships with commercial and other academic entities. When the editor has a potential conflict because of a relationship with another entity or author, the editor appoints an alternate editor from among the section editors or editorial board members who assumes the entire responsibility for final decisions on the manuscript in question. The editor does not read the reviews that are submitted nor engage in discussing the manuscript prior to the final decision. When the conflict of interest involves a section editor, a "guest section editor" is appointed who fills the role normally played by the conflicted section editor. All members of the editorial board and reviewers are asked to indicate any conflict of interest when they agree to review a manuscript. 